\title{
Pengenalan Alat Musik Gamelan Secara 3D Berbasis Augmented Reality
}

\author{
Doni Nuryanto Bakhtiar \\ Program Studi Informatika \\ Universitas Muhammadiyah Surakarta \\ Surakarta, Indonesia \\ bh.tiar98@gmail.com
}

\author{
Endah Sudarmilah \\ Program Studi Informatika \\ Universitas Muhammadiyah Surakarta \\ Surakarta, Indonesia \\ Endah.Sudarmilah@ums.ac.id
}

\begin{abstract}
Gamelan adalah salah satu jenis permainan orkestra musik tradisional asli Indonesia. Generasi muda sekarang cenderung lebih suka mempelajari musik modern dibanding musik daerahnya sendiri. Salah satu penyebabnya adalah kurang atraktifnya media pembelajaran alat musik gamelan saat ini. Untuk itu, perlu adanya media pembelajaran yang menarik agar generasi muda tertarik untuk mengenal dan mempelajari alat musik gamelan, salah satunya yaitu menggunakan teknologi Augmented Reality. Dalam penelitian ini, peneliti menerapkan teknologi Augmented Reality pada aplikasi yang berbasis mobile android sebagai pengenalan alat musik gamelan sehingga generasi muda tertarik untuk mempelajari alat musik gamelan. Dan dalam aplikasi ini disertakan juga buku yang berisi marker dan informasi dari masing-masing alat musik gamelan. Pembuatan aplikasi menggunakan software Unity3D dan Vuforia SDK dalam membangun Augmented Reality, dan software Blender dalam pembuatan objek 3 dimensinya. Dalam aplikasi ini juga disertakan kuis guna menambah pemahaman pengguna dalam mengenal alat musik gamelan.Berdasarkan hasil penelitian yang telah dilakukan menyatakan bahwa $89 \%$ responden menyatakan aplikasi mudah dioperasikan atau dimainkan, $79 \%$ responden menyatakan Tata letak tampilan aplikasi menarik, 95\% responden menyatakan materi pada aplikasi mudah dipelajari, 82\% responden menyatakan aplikasi dapat membantu belajar dalam mengenal alat musik gamelan, $90 \%$ responden menyatakan Objek 3D yang dibuat menarik, dan $93 \%$ responden menyatakan Aplikasi dapat meningkatkan keinginan untuk mempelajari alat musik gamelan. Dengan demikian tujuan dari penilian ini tercapai.
\end{abstract}

Keywords: Augmented Reality, Gamelan, Markerless, Unity3D

\section{Pendahuluan}

Indonesia memiliki kekayaan budaya yang sangat melimpah. Salah satunya adalah alat musik daerah, dimana hampir setiap daerah mempunyai alat musik khas daerahnya masing-masing.Seiring perkembangan alat musik modern yang semakin pesat, alat musik daerah kian hari semakin dilupakan. Saat ini mayoritas penikmat musik Indonesia lebih suka untuk mempelajari alat musik modern dibanding dengan alat musik daerah. Apalagi generasi muda yang seharusnya sebagai penerus bangsa malah cenderung mencintai alat musik asing daripada alat musik daerahnya sendiri. Rasa bangga dan kepedulian untuk melestarikan budaya masih kurang tertanam digenerasi muda Indonesia saat ini.

\section{TEORI DASAR}

Alat musik gamelan merupakan salah satu alat musik daerah Indonesia yang kurang diminati oleh generasi muda saat ini. Alat musik gamelan merupakan alat musik daerah yang berkembang di Jawa. Pada saat ini alat musik gamelan telah mengalami perkembangan serta sedikit modifikasi atau pertambahan beberapa alat musik modern [1]. Namun walaupun demikian minat generasi muda dalam mempelajari alat musik ini masih kurang, umumnya para pemain alat musik ini adalah para orang tua Jawa yang telah mahir memainkannya. Salah satu faktor penyebabnya adalah kurang atraktifnya media untuk mempelajari alat musik tersebut.

Pembelajaran dan pengenalan tentang alat musik gamelan perlu disajikan dengan lebih atraktif dan interaktif, karena hal ini sangat penting dalam memotivasi dan mendorong ketertarikan generasi muda untuk mempelajari alat musik gamelan. Salah satu teknologi yang sedang berkembang sekarang adalah Augmented Reality. Augmented Reality (AR) merupakan penggabungan objek virtual (teks, gambar, dan animasi) kedalam dunia nyata, dimana pengguna dapat mengeksplor dunia nyata dengan lebih atraktif dan lebih menarik [2].

Clark, dkk [3] mengemukakan bahwa, AR yang disajikan dalam bentuk buku dapat memungkinkan pembaca untuk berinteraksi dan tertarik dengan isi buku, sehingga dapat menolong pembaca dalam memahami materi yang ada pada buku. Dalam pembuatan AR memerlukan sebuah marker. Marker adalah penanda yang digunakan agar aplikasi AR dapat melacak dan mendeteksi orientasi serta melakukan penyesuaian posisi objek 3D yang nantinya akan ditangkap oleh kamera. 
Menurut Wahyudi, dkk [4]. Secara umum teknik AR yang dapat diterapkan dalam buku adalah fiduciary marker dan markerless. Fiduciary marker menggunakan marker yang masih berupa gambar kotak hitam putih untuk memunculkan obyek AR. Sedangkan Markerless dalam memunculkan objek AR-nya tanpa harus menggunakan marker yang spesial, sehingga teknik markerless memungkinkan untuk dapat melacak hampir semua jenis gambar yang ada di dunia nyata.

Salah satu platform yang mendukung teknik markerless adalah vuforia SDK yang pemanfaatnya bisa digunakan pada smartphone[5][6]. Berdasarkan permasalahan tersebut muncul sebuah gagasan untuk melakukan penelitian dengan judul "Pengenalan Alat Musik Gamelan secara 3D Berbasis Augmented Reality dengan Teknik Markerless Menggunakan Media Buku".

\section{METODE}

Alur penelitian dapat digambarkan seperti gambar 1 .

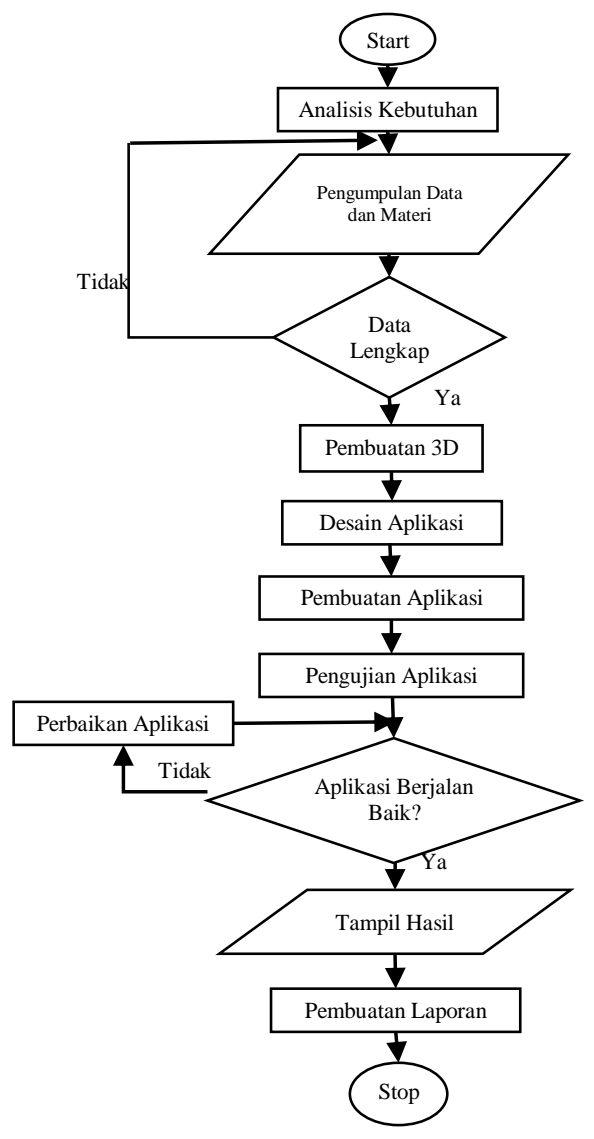

Gambar 1 Flowchart Alur Penelitian

Keterangan :

1. Analisis kebutuhan: Tahap menentukan saranaprasarana yang dibutuhkan dalam perancangan dan pembangunan aplikasi Augmented Reality untuk pengenalan alat musik gamelan.
2. Pengumpulan Data : Pengumpulan data yang dibutuhkan dalam pembuatan aplikasi Augmented Reality untuk pengenalan alat musik gamelan sesuai dengan analisis kebutuhan.

3. Pembuatan 3D : Pembuatan Objek 3D alat musik gamelan.

4. Desain Aplikasi : Aplikasi dirancang dengan mengedepankan Augmented Reality sebagai media untuk pengenalan alat musik gamelan, serta ditambahkan dengan kuis agar user lebih memahami materi yang ada dalam aplikasi.

5. Pembuatan Aplikasi : Membuat aplikasi sesuai dengan desain yang telah dibuat dan data yang telah terkumpul serta dengan menggunakan beberapa software dan hardware. Pembuatan marker dibuat dengan software Corel Draw dan Adobe Photoshop, aplikasi AR dibuat dengan menggunakan software Unity3D.

6. Pengujian Aplikasi : Pengujian meliputi pengujian black-box yaitu pengujian fungsifungsi pada aplikasi, serta pengujian kuesioner yang dilakukan di Sekolah Dasar. Apabila aplikasi tidak sesuai dengan tujuan maka akan dilakukan perbaikan aplikasi.

7. Laporan : Proses pengembangan aplikasi Augmented Reality untuk pengenalan alat musik gamelan setiap tahapnya didokumentasikan dalam bentuk gambar dan teks tertulis yang disusun sesuai dengan format laporan.

\section{HASIL DAN PEMBAHASAN}

Aplikasi Augmented Reality untuk pengenalan alat musik gamelan dibangun menggunakan software Unity3D v4.5.2 dimana unity merupakan software yang terintegrasi untuk membuat game, simulasi dan bangunan arsitektur, serta Unity mendukung berbagai platform seperti PC, Mac, Wii, iPhone, Ipad, Android, dan browser. [7], Vuforia SDK v3.0.9 untuk pembuatan Augmented Reality dan software Blender v2.67b untuk pembuatan objek 3D. Aplikasi ini dibangun menggunakan pemrograman visual menggunakan assets dari Unity3D yaitu Playmaker v1.7.7 yang menggunakan FSM (Finite State Machine). Peneliti menggunakan NGUI v3.7.0 untuk perancangan antarmuka aplikasi serta Mad Level v2.2.4 untuk perancangan level pada halaman quiz yang juga merupakan assets dari Unity3D.

\section{Halaman Menu Utama}

Halaman Utama merupakan halaman yang ditampilkan pada saat pertama kali aplikasi dijalankan. Halaman Utama terdiri dari beberapa pilihan menu yang dapat dipilih oleh user dengan cara menekan tombol pilihan yang tersedia. Tombol diberi efek animasi dan efek suara agar lebih menarik seperti pada Gambar 2. 


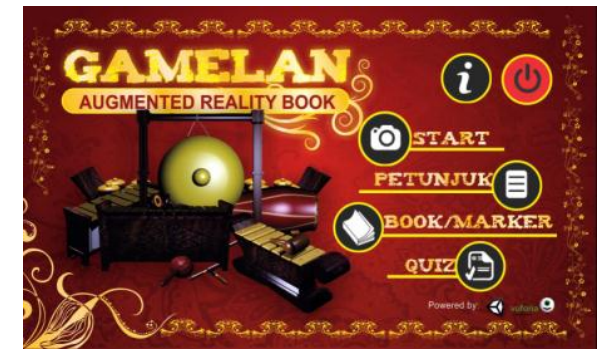

Gambar 2 Halaman Menu Utama

Halaman Utama terdapat 6 (empat) menu yang merupakan 4 tombol beserta keterangan tombol dan 2 tombol tanpa keterangan tombol, 4 menu tersebut yaitu Start, Petunjuk, Book/Marker, dan Quiz. Sedangkan 2 (dua) tombol yaitu About dan Exit. Halaman ini dibangun menggunakan asset Unity3D, NGUI untuk membangun tampilan antarmuka dan Playmaker yang merupakan asset pemrograman visual untuk mengaktifkan tombol-tombol yang tersedia.

\section{Halaman Menu Start}

Halaman Menu Start merupakan merupakan halaman inti dalam aplikasi Augmented Reality untuk pengenalan alat musik gamelan ini. Pada halaman ini Augmented Reality diterapkan untuk pengenalan alat musik gamelan dimana penggunaanya menggunakan marker untuk memunculkan objek alat musik gamelan 3D. Terdapat 13 marker yang masing-masing marker mewakili jenis alat musik gamelan yang akan ditampilkan yaitu Kendhang, Gong, Saron-DemungPeking, Gambang, Bonang, Kempul, Kenong, Kethuk-kempyang, Gender, Slenthem, Siter, Rebab, dan Suling.

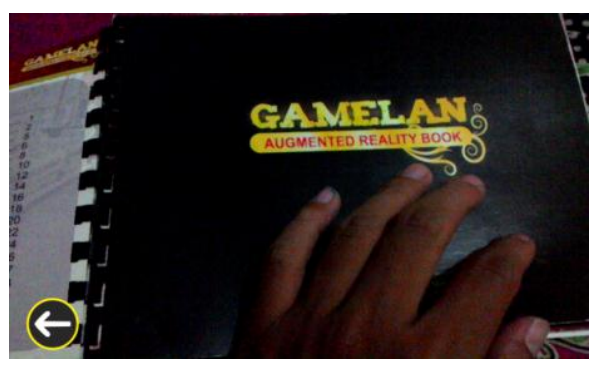

Gambar 3 Halaman Menu Start

Pada Halaman Menu Start terdapat tombol suara untuk mendengarkan suara masing-masing alat musik gamelan yang ditampilkan dan tombol back untuk kembali ke Halaman Menu Utama, serta terdapat slider rotasi untuk memutar alat musik gamelan yang ditampilkan.

\section{Halaman Menu Petunjuk}

Halaman Menu Petunjuk merupakan halaman yang berisi panduan cara penggunaan aplikasi Augmented Reality untuk pengenalan alat musik gamelan seperti pada Gambar 4. Diharapkan dengan adanya menu ini dapat membantu user dalam mengoperasikan aplikasi. Dalam menu petunjuk terdapat tombol back yang apabila ditekan aplikasi akan kembali ke Halaman Menu Utama.

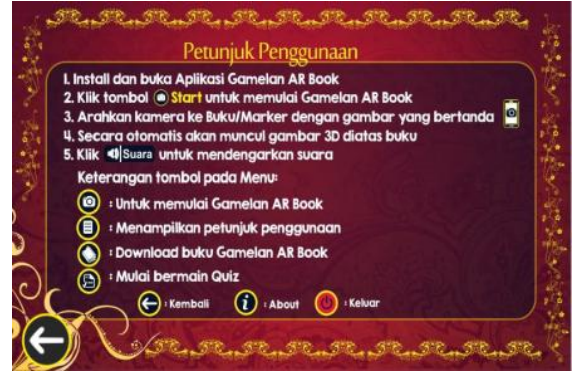

Gambar 4 Halaman Menu Petunjuk

\section{Halaman Menu Book/Marker}

Halaman Book/Marker berisi penjelasan tentang fungsi marker pada aplikasi Augmented Reality untuk pengenalan alat musik serta link download untuk mengunduh marker berbentuk buku yang telah disediakan oleh peneliti. Dalam menu ini terdapat dua tombol yaitu tombol Back yang apabila ditekan akan kembali ke Halaman Menu Utama, dan tombol Download yang apabila ditekan akan menampilkan browser menuju link untuk mengunduh marker. Secara detail dapat dilihat pada Gambar 5.

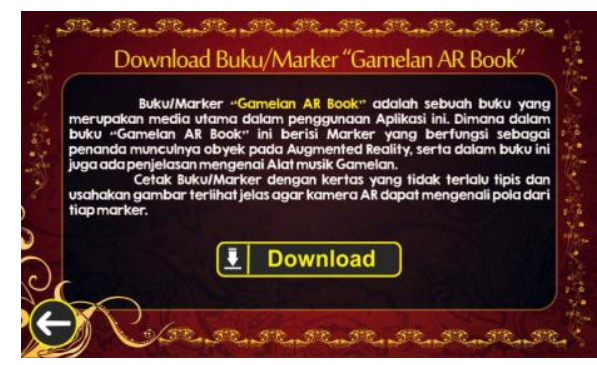

Gambar 5 Halaman Menu Book/Marker

\section{Halaman Menu Quiz}

Halaman Menu Quiz merupakan halaman yang berisi dua sub-halaman yaitu Halaman AR Quiz dan Halaman Regular Quiz seperti ditunjukkan pada Gambar 6. Halaman AR Quiz merupakan halaman kuis dengan soal menggunakan Augmented Reality dan dengan marker khusus yang digunakan untuk AR Quiz yang bertujuan agar user lebih memahami masing-masing bentuk dari alat musik gamelan. Sedangkan pada halaman Reguler Quiz berisi soalsoal model pilihan ganda yang bertujuan agar user lebih memahami materi yang ada dalam buku. Dalam menu ini juga terdapat tombol Back untuk kembali ke Halaman Menu Utama.

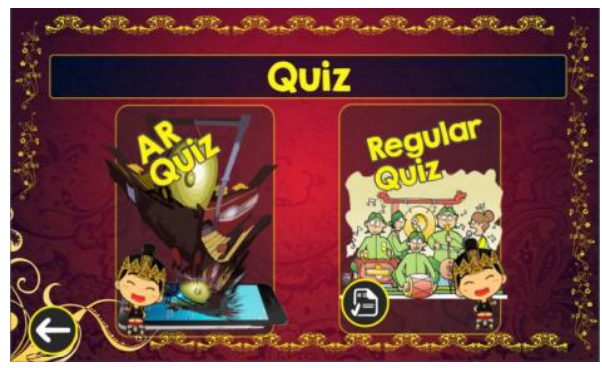

Gambar 6 Halaman Menu Quiz

\section{Halaman Menu About}


Halaman Menu About merupakan halaman yang berisi informasi tentang pengembangan aplikasi Augmented Reality untuk pengenalan alat musik gamelan dan profil pengembang seperti yang ditunjukkan pada gambar 7 .

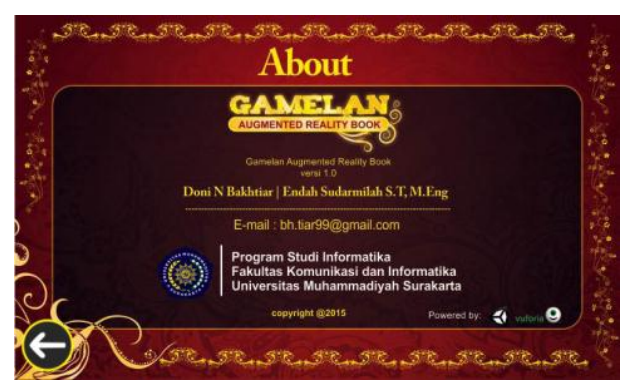

Gambar 7 Halaman Menu About

\section{Halaman Menu Exit}

Halaman Exit merupakan halaman yang berisi dialog antara user dengan sistem untuk mengambil keputusan keluar aplikasi atau tidak.

Pengujian aplikasi dilakukan untuk mengetahui apakah aplikasi yang dibuat sudah berjalan dengan baik sesuai dengan fungsinya atau tidak sebelum dilakukan penilaian oleh responden. Peneliti menggunakan metode black-box untuk mengetahui apakah aplikasi sudah berjalan sesuai dengan fungsinya. Dari hasil uji blackbox diperoleh bahwa seluruh bagian yang diuji memperoleh hasil status keberhasilan Ok.

Setelah selesai dilakukan pengujian blackbox selanjutnya yaitu dilakukan pengujian validitas dan reliabilitas dengan menyebar kuesioner yang dilakukan di Sekolah dasar dengan 26 siswa. Berdasarkan hasil pengujian kuesioner diperoleh hasil uji validitas pada Tabel 1 .

Tabel 1 Hasil Uji Validitas Kuesioner

\begin{tabular}{|c|c|c|c|}
\hline Korelasi Antara & Nilai Korelasi & Nilai r tabel & Kesimpulan \\
\hline P1 dengan Total & 0.658 & 0.388 & Valid \\
\hline P2 dengan Total & 0.660 & 0.388 & Valid \\
\hline P3 dengan Total & 0.687 & 0.388 & Valid \\
\hline P4 dengan Total & 0.597 & 0.388 & Valid \\
\hline P5 dengan Total & 0.642 & 0.388 & Valid \\
\hline P6 dengan Total & 0.678 & 0.388 & Valid \\
\hline
\end{tabular}

Keterangan :

P1 : Aplikasi mudah dioperasikan/dimainkan

P2 : $\quad$ Tata letak tampilan aplikasi menarik

P3 : $\quad$ Isi materi mudah dipelajari/dimengerti

P4 : Aplikasi dapat membantu belajar mengenal alat musik gamelan

P5 : $\quad$ Objek 3D yang dibuat menarik

P6 : Aplikasi dapat meningkatkan keinginan untuk mempelajari alat musik gamelan

Berdasarkan hasil perhitungan di atas maka semua pernyataan pada kuesioner dinyatakan valid.
Selanjutnya pernyataan-pernyataan yang telah valid dilakukan uji reliabilitas untuk menyatakan bahwa hasil kuesioner dapat dipercaya. Berikut hasil uji reliabilitas pada tabel 2 .

Dapat dilihat dari hasil uji reliabilitas pada Tabel 2 bahwa nilai reliabilitas menunjukkan angka sebesar 0,710. Menurut Arikunto [8] nilai reliabilitas sebesar 0,710 berarti mempunyai tingkat reliabilitas yang diuji termasuk kategori tinggi.

Tabel 2 Hasil Uji Reliabilitas
Reliability Statistics
\begin{tabular}{|r|r|}
\hline Cronbach's Alpha & N of Items \\
\hline .710 & \\
\hline
\end{tabular}

Kemudian data hasil dari kuesioner dilakukan penghitungan persentase rata-rata interpretasi. Tabel 3 dan Gambar 8 menunjukkan hasil penghitungan persentase rata-rata interpretasi beserta diagram berdasarkan kuesioner yang diisi oleh responden dengan hasil pada setiap kriteria menunjukkan hasil diatas $80 \%$ kecuali pada komponen tata letak tampilan aplikasi yang dinilai $79 \%$ sebagai salah satu aplikasi seious game [9].

Tabel 3 Hasil Persentase Interpretasi Siswa

\begin{tabular}{|c|c|c|c|c|c|c|c|c|}
\hline \multirow[b]{2}{*}{ No } & \multirow[b]{2}{*}{ Pernyataan } & \multicolumn{5}{|c|}{$\begin{array}{c}\text { Pernyataan dan Jumlah } \\
\text { jawaban }\end{array}$} & \multirow[b]{2}{*}{$\begin{array}{l}\text { Jumlah Skor } \\
\text { (S) }\end{array}$} & \multirow{2}{*}{$\begin{array}{l}\text { Persentase } \\
\text { Intepretasi } \\
\text { (P) }\end{array}$} \\
\hline & & $\begin{array}{l}\text { SS } \\
\text { (5) }\end{array}$ & $\begin{array}{l}\mathrm{S} \\
\text { (4) }\end{array}$ & $\mathrm{N}$ & $\begin{array}{l}\text { TS } \\
\text { (2) }\end{array}$ & $\begin{array}{l}\text { STS } \\
\text { (1) }\end{array}$ & & \\
\hline 1. & P1 & 16 & 6 & 4 & 0 & 0 & 116 & $89 \%$ \\
\hline 2. & P2 & 4 & 17 & 5 & 0 & 0 & 103 & $79 \%$ \\
\hline 3. & P3 & 21 & 3 & 2 & 0 & 0 & 123 & $95 \%$ \\
\hline 4. & P4 & 12 & 4 & 10 & 0 & 0 & 106 & $82 \%$ \\
\hline 5. & P5 & 14 & 11 & 1 & 0 & 0 & 117 & $90 \%$ \\
\hline 6. & P6 & 19 & 5 & 2 & 0 & 0 & 121 & $93 \%$ \\
\hline
\end{tabular}

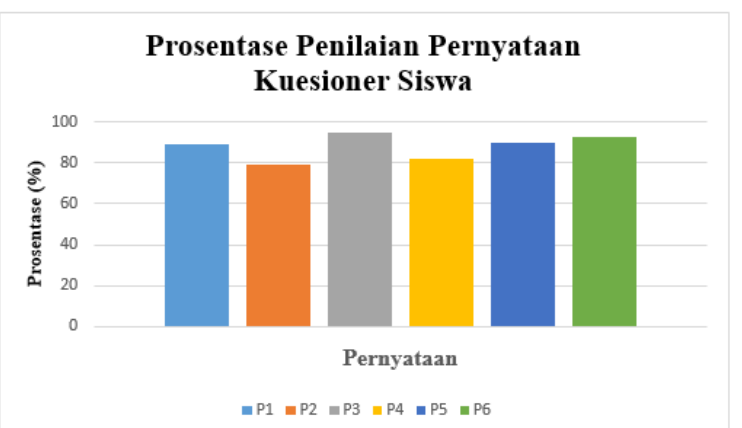

Gambar 8 Persentase Pernyataan Kuesioner

\section{KESIMPULAN}

Kesimpulan dari penelitian ini yaitu berhasil dibuat dengan baik Aplikasi Pengenalan Alat Musik Gamelan menggunakan Augmented Reality berbasis Android. Berdasarkan pengujian yang dilakukan terhadap responden diperoleh hasil yaitu sebanyak 89\% siswa menyatakan aplikasi mudah dioperasikan atau dimainkan, 79\% siswa menyatakan Tata letak tampilan aplikasi menarik, 95\% siswa menyatakan 
materi pada aplikasi mudah dipelajari, 82\% siswa menyatakan aplikasi dapat membantu belajar dalam mengenal alat musik gamelan, 90\% siswa menyatakan Objek 3D yang dibuat menarik, dan $93 \%$ siswa menyatakan Aplikasi dapat meningkatkan keinginan untuk mempelajari alat musik gamelan. Berdasarkan kesimpulan yang sudah diuaraikan diatas maka Tujuan penelitian yaitu menerapkan Augmented Reality dalam pengenalan alat musik gamelan yang sebagai alternatif pembelajaran yang menarik

\section{UCAPAN TERIMA KASIH}

Karya ini didukung oleh Program Studi Informatika, Universitas Muhammadiyah Surakarta dan Ristekdikti.

\section{DAFTAR PUSTAKA}

[1] Apriansyah, R (2014). Aplikasi Pengenalan Alat Musik Tradisional Gamelan Untuk Anak-Anak Menggunakan Blender. Skripsi thesis, Universtas Muhammadiyah Surakarta.

[2] Azuma, R.T (1997). A Survey of Augmented Reality. In Presence: Teleoperators and Virtual Enviorenment 6, 355-385.

[3] Clark, A., Dunser, A, Grasset, R (2012). An Interactive Augmented Reality Coloring Book. 2012 IEEE Symposium on 3D User Interfaces (3DUI), 7-10.

[4] Wahyudi, A.K., Ferdiana., R, Hartanto R (2013). ARca: Perancangan Buku Interaktif Berbasis Augmented Reality pada Pengenalan dan Pembelajaran Candi Prambanan dengan Smartphone Berbasis Android. Seminar Nasional Ithink Smart-2013, 227-235

[5] Januanesbi, Galan (2014). Pembelajaran Vulkanologi Secara 3D Berbasis Augmented Reality. Skripsi thesis, Universitas Muhammadiyah Surakarta.

[6] Rimahirdani, Farissa., Ade Eviyanti. (2014). Aplikasi Augmented Reality Pengenalan Alat Musik Gamelan Jawa. Sidoarjo: Universitas Muhammadiyah Sidoarjo.

[7] Sudarmilah, Endah., R. Ferdiana., L. E. Nugroho., A. Susanto. 2013. Tech review: Game platform for upgrading counting ability on Preschool Children. Prosiding on The 5th International Conference on Information Technology and Electrical Engineering (ICITEE 2013).

[8] Arikunto. (1998). Prosedur Penelitian; Suatu Pendekatan Praktik. Jakarta : Rineka Cipta.

[9] E. Sudarmilah, U. Fadlilah, H. Supriyono, F. Y. A. Irsyadi, Y. S. Nugroho, and A. Fatmawati, "A review: Is there any benefit in serious games?," in AIP Conference Proceedings, 2018, vol. 1977. 